\title{
METHOD DEVELOPMENT AND VALIDATION FOR ANALYSIS OF DEOXYARBUTININ ANHYDROUS EMULSION SYSTEM USING HIGH-PERFORMANCE LIQUID CHROMATOGRAPHY
}

\author{
MUCHTARIDI MUCHTARIDI*, IDA MUSFIROH, AHMAD FAUZI
}

Department of Pharmaceutical Analysis and Medicinal Chemistry, Faculty of Pharmacy Universitas Padjadjaran, Sumedang, Indonesia Email: muchtaridi@unpad.ac.id

Received: 25 Oct 2018, Revised and Accepted: 30 Jan 2019

\section{ABSTRACT}

Objective: The aim of this study is to develop a simple, precise and accurate analytical method of deoxyarbutin in anhydrous emulsion system preparation.

Methods: The analysis was conducted using high-performance liquid chromatography (HPLC). Chromatographic analysis was carried out using a reversed phase-C18 column. The mobile consists of two phases methanol and water (60:40 v/v) at a flow rate of $1.0 \mathrm{ml} / \mathrm{min}$. The determinations were performed using UV detector set at $225 \mathrm{~nm}$. All validation procedures were added with hydroquinone as an internal standard.

Results: The method showed coefficient correlation is 0.9978, relative standard deviation (RSD) smaller than 2\%, Limit of Detection (LOD) and Limit of Quantitation (LOQ) are $0.599 \mu \mathrm{g} / \mathrm{ml}$ and $1.817 \mu \mathrm{g} / \mathrm{ml}$ respectively. The total amount deoxyarbutin in anhydrous emulsion preparation is $1.964+0.02 \%$ with $98 \%$ recovery percentage.

Conclusion: The developed HPLC analytical method meets the validation criteria made by International Conference on Harmonisation (ICH).

Keywords: Analytical method validation, Anhydrous emulsion, Deoxyarbutin

(C) 2019 The Authors. Published by Innovare Academic Sciences Pvt Ltd. This is an open-access article under the CC BY license (http://creativecommons.org/licenses/by/4.0/) DOI: http://dx.doi.org/10.22159/ijap.2019v11i2.30461

\section{INTRODUCTION}

Deoxyarbutin was first synthesized in 2005 by Boissy and his team. This compound is synthesized from its parent compound arbutin by removing the hydroxy group on the glucose side chain [1]. Deoxyarbutin is a novel depigmentation agent which has tyrosinase inhibitor activity. This compound inhibits melanin synthesis in melanogenesis [2]. Excessive melanin accumulation causes hyperpigmentation. This condition is not considered cosmetically pleasing to most people [3]. Hyperpigmentation is the changing of the color intensity of the skin to darker, which is due to an increased amount of melanin in the epidermis, the dermis, or both. This change can be due to 2 pathophysiologic processes: melanocytosis (increased number of melanocytes) and melanosis (increased amount of melanin). Skin lightening agents work best when melanosis or melanocytosis is confined to the epidermis $[4,5]$. A strategy for the treatment of hyperpigmentation conducted through a depigmentation agent [6]. Skin depigmentation agents are widely developing through inhibition of tyrosinase enzyme [7]. The tyrosinase enzyme is responsible for catalyzing the conversion of Ltyrosine into L-DOPA in melanogenesis, inhibition of tyrosinase enzyme causing disruption of melanin formation [8]. Deoxybarbutin has been shown to have better activity than other tyrosinase inhibitor agents and also safer $[1,8]$. Some depigmentation agents were used before are hydroquinone, arbutin and kojic acid [9-11].<smiles>Oc1ccc(OC2CCCCO2)cc1</smiles>

Fig. 1: Chemical structure of deoxyarbutin

In previous studies, it was stated that deoxyarbutin is thermolabile in aqueous solution and decomposes into hydroquinone. Instability in water is a problem if formulated in conventional emulsions. Therefore, to enhance the stability, the aqueous phase formulated to an anhydrous, non-aqueous, oil-in-oil or oil-polar solvent emulsion system [13-14]. In this preparation, we choose polyol-in-oil anhydrous emulsions for the analysis. Propylene glycol and glycerin provide the solubility of deoxyarbutin. The oil phase is produced by adding cyclomethicone with stearyl dimethicone and isostearyl isostearate. The major objective of this study was to obtain a simple, rapid and accurate analytical method deoxyarbutin in the anhydrous emulsion system. Method development was conduct with highperformance liquid chromatography (HPLC). An internal standard method is used for methodological development.

\section{MATERIALS AND METHODS}

\section{Materials}

\section{Chemical reagent}

Deoxyarbutin (Nardev Chemie), Hydroquinone (Xilong Chemical) as an internal standard, Methanol pro-HPLC (Merck), aquabidest (IPHA Laboratories), cetyl dimethicone copolyol, cyclomethicone, stearyl dimethicone, isostearyl isostearat, propylene glycol and glycerin.

\section{Apparatus and chromatographic conditions}

HPLC (Shimadzu) with UV detector (Shimadzu), analytical scales (Ohauss Pioneer), ultrasonic bath (NEY 1510), C18G Enduro column (SGE analytical) with a C18 guard column (SGE analytical), micro filter syringe (Hamilton Co.) and LC solution for data interpretation. The HPLC system operated at $25^{\circ} \mathrm{C}$ with methanol and water (60: $40 \mathrm{v} / \mathrm{v}$ ) as mobile phase with isocratic elution. The flow rate is 1 $\mathrm{ml} / \mathrm{min}$. The injection volume is $10 \mu \mathrm{l}$. UV detection performed at $225 \mathrm{~nm}$. The total run time for HPLC analysis is $8 \mathrm{~min}$.

\section{Methods}

Preparation of standard solution

Stock standard of deoxyarbutin $(500 \mu \mathrm{g} / \mathrm{ml})$ and hydroquinone (500 $\mu \mathrm{g} / \mathrm{ml}$ ) were prepared by dissolving $25 \mathrm{mg}$ deoxyarbutin and hydroquinone in $50 \mathrm{ml}$ mobile phase and stored in the refrigerator. The working solution was made by diluting the stock standard solution in the mobile phases into several concentrations of 6.25 , $12.5,25,50,80,100,120$ and $200 \mu \mathrm{g} / \mathrm{ml}$. All working standards contain internal standard hydroquinone $25 \mu \mathrm{g} / \mathrm{ml}$.

\section{Mobile phase preparation}

The mobile phase consists of methanol and water $(60: 40 \mathrm{v} / \mathrm{v})$. The mobile phase was degassed to remove air bubbles in the mobile phase. The mobile phase was filtered using a $0.45 \mu \mathrm{m}$ membrane filters after sonicated using ultrasonic for $10 \mathrm{~min}$. 


\section{Procedure validation with HPLC method}

The validation method was developed according to ICH (Q2) guideline validation of analytical procedures [15]. System suitability was conducted by injecting six replicated standards of deoxyarbutin. Linearity was observed using six solutions concentration of standard $(6.25,12.5,25,50,100$ and $200 \mu \mathrm{g} / \mathrm{ml})$. Accuracy (recovery) was determined using three levels concentration of standard deoxyarbutin 80,100 and $120 \%(80,100,120 \mu \mathrm{g} / \mathrm{ml})$ with three replications. The precision was investigated by respect to repeatability (intra-day precision) and intermediate precision (inter-day variation) by measured concentration of standard deoxyarbutin $100 \%(100 \mu \mathrm{g} / \mathrm{ml})$ with six replications. The limit of detection (LOD) and limit of quantitation (LOQ) of deoxyarbutin were determined based on the standard deviation $(\sigma)$ of response and slope (s). All standard concentrations of deoxyarbutin for validation procedure spiked with internal standard hydroquinone 25 $\mu \mathrm{g} / \mathrm{ml}$ and excipient of preparation or placebo.

\section{The analysis of deoxyarbutin in anhydrous emulsion preparation}

A cream sample $(2.5 \mathrm{~g}$ ) was dissolved in $100 \mathrm{ml}$ methanol and then sonicated for $30 \mathrm{~min}$. $2.5 \mathrm{ml}$ sample diluted with $25 \mathrm{ml}$ of mobile phase. The sample was filtered by a membrane filter of $0.45 \mu \mathrm{m}$ and injected to HPLC system.

\section{RESULTS AND DISCUSSION}

\section{Method development and optimization}

The choice of the mobile phase is generally based on the polarity index ( $\mathrm{P}$ '), hence it can elute the analyte from the column. The higher $\mathrm{P}$ value indicates the more polar mobile phase. To get the mobile phase with medium polarity, a combination of two or more mobile phases is performed. The mobile phase used is a combination of methanol and water. Methanol is a semipolar solvent. The polarity index of methanol and water respectively 5.1 and 10.2 [16]. Deoxyarbutin is a hydrophobic compound because the hydroxy group removed from the side chain of the glucose group of the parent compound, arbutin [1]. Deoxyarbutin can dissolve in methanol with the solubility of $667 \mathrm{~g} / \mathrm{L}$ at $24{ }^{\circ} \mathrm{C}$. Hydroquinone used as an internal standard has more polar properties than deoxyarbutin with a $\log \mathrm{P}$ value of 0.59 at a temperature of $25^{\circ} \mathrm{C}$ (PubChem CID 785).

The combination of methanol and water with a 60: 40 composition can dissolve and remove both deoxyarbutin and hydroquinone from the column. The column used for separated deoxyarbutin and hydroquinone is reversed phase column C18. In the reverse phase column, the stationary phase is octadecyl silica. It is caused by nonpolar compounds to be absorbed in the column longer. Therefore, in this analysis, hydroquinone is eluted prior to deoxyarbutin. The use of guard columns is aimed to protect the column from damage caused by chemical contamination, without affecting the results of the analysis. Contamination or impurity can be carried by the mobile phase contaminated from samples, solvents, or substances from the pump. The existence of this contamination causes disturbances, such as high back pressure, formed peaks that are divided or expanded, the disturbed baseline either drifts or decreases, and the most common is the change in resolution or separation of the columns. Analytical method validation with HPLC was developed by internal standard method. Internal standard methods are used to improve the precision and accuracy of results where volume errors are difficult to predict and control the analytical methods [17]. The error of analysis is caused by injection errors, solvent evaporation and the preparation in the analytical procedure. In this study, hydroquinone is chosen as an internal standard. UV detector sets at $225 \mathrm{~nm}$ to detect deoxyarbutin and hydroquinone. Both of these compounds have a chromophore group that can be detected on UV wavelength.

In this study, a simple mixed of mobile phase containing methanol: water $(60: 40 \mathrm{v} / \mathrm{v})$ can separate these two compounds within $8 \mathrm{~min}$ in its preparation. Methanol has intermediate polarity and combination with water can elute this hydrophobic compound from C18 Column [18]. This method is more efficient compared to several studies which examine the separation of deoxyarbutin and hydroquinone using HPLC with a conditioned mobile phase, such as methanol and water at 80:20 (v/v) and acetonitrile-water-formic acid at the various ratio and with spectrophotometric method [19].

\section{Validation methods}

System suitability test (SST) is an essential feature in analytical method validation. SST mainly determines Resolution (R), repeatability (RSD-relative standard deviations of peak response and retention time), column efficiency $(\mathrm{N})$, capacity factor and tailing factor (T) [15]. SST is generally performed to evaluate the suitability and the effectiveness of the entire chromatographic system. Not only it is initially used but also used during the analysis. The proposed method meets these requirements within the accepted limits as shown in table 1. The chromatogram standard deoxyarbutin and IS hydroquinone is described in fig. 2. Deoxyarbutin and hydroquinone are separated completely, and there is no interference placebo preparation or matrix on their chromatogram.

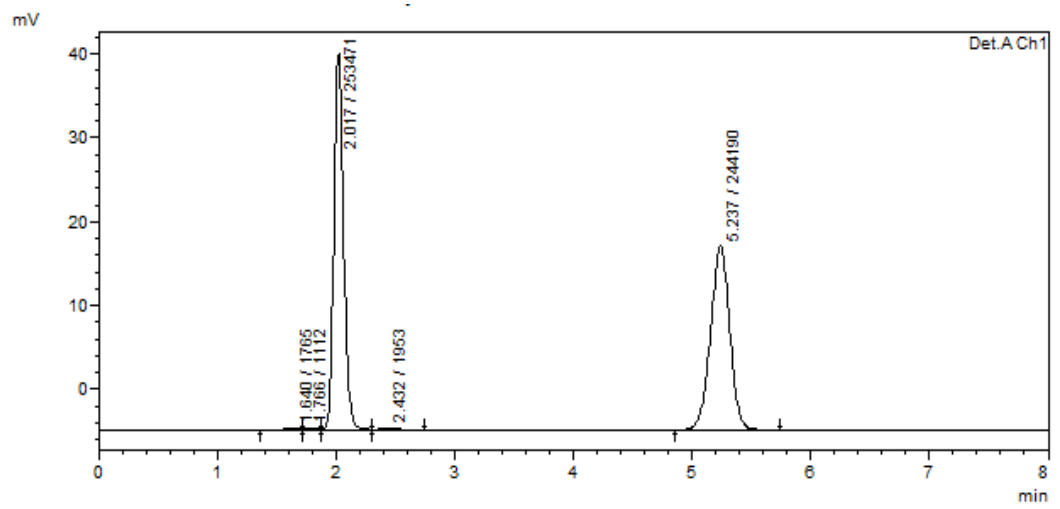

Fig. 2: Chromatogram standard of deoxyarbutin $50 \mu \mathrm{g} / \mathrm{ml}(5.237 \mathrm{~min})$ and internal standard hydroquinone $25 \mu \mathrm{g} / \mathrm{ml}(2.017 \mathrm{~min})$. The Xaxis is retention time and $\mathrm{Y}$-axis is AUC

Table 1: Results of parameters of system suitability test

\begin{tabular}{|c|c|c|c|}
\hline \multirow[t]{2}{*}{ Parameters } & \multirow[t]{2}{*}{ Recommended limit } & \multicolumn{2}{|l|}{ Result } \\
\hline & & Hydroquinone & Deoxyarbutin \\
\hline \multirow[t]{2}{*}{ Injection repeatability $(n=6)$} & $\mathrm{RSD}<2 \%$ for $\mathrm{n} \geq 5$ & RSD of area: $0.146 \%$ & RSD of area: $0.197 \%$ \\
\hline & & RSD of retention time: $0.06 \%$ & RSD of retention time: 0.121 \\
\hline Plate number $(\mathrm{N})$ & $\mathrm{N}>2000$ & 2,508 & 4,592 \\
\hline Capacity factor $(\mathrm{K})$ & $<\mathrm{k}^{\prime}<10$ & 0.299 & 2.192 \\
\hline Tailing factor $(\mathrm{T})$ & $\mathrm{T} \leq 2$ & 1.17 & 1.16 \\
\hline
\end{tabular}


Linearity was studied using six standards of deoxyarbutin spiked with IS hydroquinone. Each variation concentration was injected into HPLC system in triplicate. The calibration curve was constructed by plotting between ratio concentration of deoxyarbutin $(\mathrm{x})$ and hydroquinone and ratio peak area $(\mathrm{y})$. The correlation coefficient $\left(\mathrm{r}^{2}=0.9978\right)$ obtained for the regression line demonstrates that there is a strong linear relationship between peak area and concentration of deoxyarbutin (fig. 3). Limit of Detection (LOD) and Limit of Quantification present the sensitivity of the analytical method. LOD is the point at which a measured value is larger than the uncertainty associated with it. It is the lowest concentration of an analyte in a sample that can be detected, but not necessarily quantified. LOQ is the minimum injected amount that produces quantitative measurements in the target matrix with acceptable precision in chromatography, typically requiring peak heights 10 to 20 times higher than the baseline noise. LOD and LOQ were calculated by using the following equations: $\mathrm{LOD}=(3.3 \sigma / \mathrm{s}), \mathrm{LOQ}=(10 \sigma / \mathrm{s})[19]$. LOD and LOQ deoxyarbutin in this analytical method are found consecutively 0.599 $\mu \mathrm{g} / \mathrm{ml}$ and $1.817 \mu \mathrm{g} / \mathrm{ml}$.

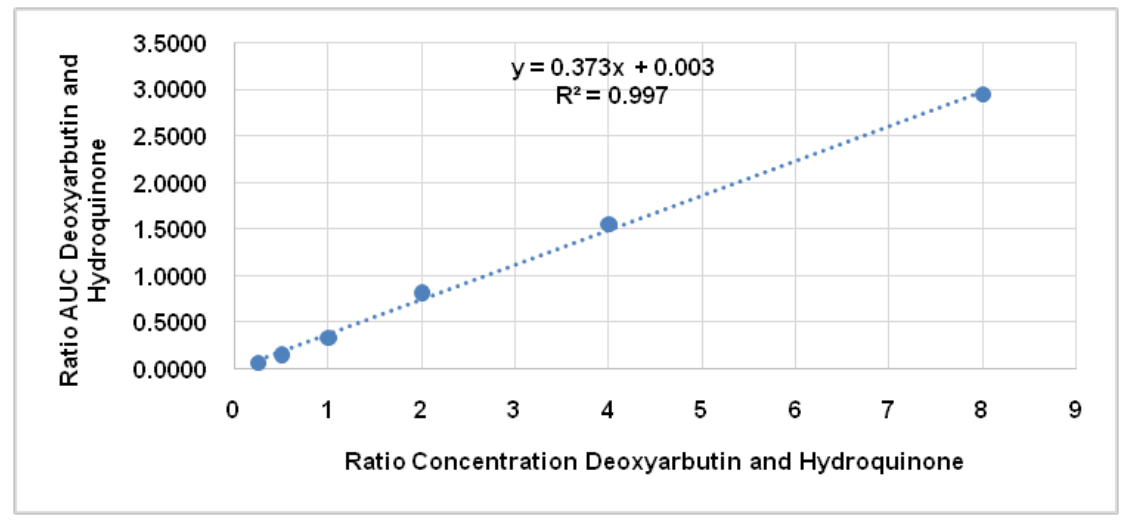

Fig. 3: Calibration curve of deoxyarbutin with an internal standard method

Repeatability (intra-day) and intermediate precision (inter-day variation) are shown in table 2 . Precision is presented as \% RSD.
Precision was determined by placebo spiked method. \% RSD for repeatability is $1.90 \%$ and $\%$ RSD for intermediate precision is $1.27 \%$.

Table 2: Result repeatability and intermediate precision

\begin{tabular}{lllll}
\hline Precision & Parameters & Concentration $(\boldsymbol{\mu g} / \mathbf{m l})$ & Acceptance criteria & $\begin{array}{l}\text { Results } \\
(\mathbf{m e a n} \pm \text { SD) }\end{array}$ \\
\hline Repeatability & & & $\%$ RSD $<2$ & $1.90 \pm 1.93$ \\
Intermediate precision & $\%$ RSD & 100 & $\%$ RSD $<2$ & $1.27 \pm 0.56$ \\
\hline
\end{tabular}

*Precision value is represented as a mean \pm SD (standard deviation) of 6 observation $(n=6)$ on level $100 \%$.

Table 3: Recovery studies deoxyarbutin with placebo spiked method

\begin{tabular}{llll}
\hline Level (\%) & Deoxyarbutin added (mg) & Deoxyarbutin founded (mg) & Recovery (\%) (mean \pm SD) \\
\hline 80 & 39.8 & 37.5 & $96.3+1.19$ \\
& 40.0 & 38.9 & \\
100 & 40.2 & 39.2 & $102.4+0.6$ \\
& 50.1 & 51.6 & \\
120 & 50.2 & 51.1 & $97.8+0.9$ \\
& 50.1 & 51.4 & \\
\hline
\end{tabular}

*Accuracy value is represented as a mean $\pm \mathrm{SD}$ (standard deviation) of 3 observation $(n=3)$ each level.

The aim of study accuracy is to investigate the analytical method that is able to provide accurate result value. Accuracy can also be described as the closeness between the founding value and the true value. Accuracy reported by percentage recovery. Same as the precision study, accuracy is determined by placebo spiked method. Accuracy meets criteria validation. As the result of recovery percentage shown in table 3.

\section{Analysis deoxyarbutin in anhydrous emulsion preparation}

Table 4 shows the level of deoxyarbutin in anhydrous emulsion preparation. $2.5 \mathrm{~g}$ emulsion is dissolved in $100 \mathrm{ml}$ methanol, and added by $25 \mu \mathrm{g} / \mathrm{ml}$ internal standard hydroquinone. Methanol solvent used for extracting deoxyarbutin from other components [12]. To speed up the extraction process, the process is assisted by sonication, using ultrasonic for $15 \mathrm{~min}$. Sonication aims to increase the homogeneity of dissolving particles that may still be present in the matrix by increasing kinetic energy from the particle. $2.5 \mathrm{ml}$ samples are diluted with $25 \mathrm{ml}$ of mobile phase. The sample is filtered by a membrane filter of $0.45 \mu \mathrm{m}$ and injected to HPLC system. The deoxyarbutin concentration in preparation is determined by making a substitution of the peak area ratio between deoxyarbutin and hydroquinone to regression linear. The total of deoxyarbutinin anhydrous emulsion preparation $(n=3)$ is $1.96 \pm 0,02$ $\%$ with $98 \%$ recovery. 
Table 4: The content of deoxyarbutin in anhydrous emulsion preparation

\begin{tabular}{|c|c|c|c|c|}
\hline \multirow[t]{2}{*}{ Replication \# } & \multicolumn{2}{|l|}{ Peak area } & \multirow[t]{2}{*}{ Ratio peak area } & \multirow[t]{2}{*}{ Percentage of Deoxyarbutin (\%) } \\
\hline & Deoxyarbutin & Hydroquinone & & \\
\hline 1 & 650336 & 221654 & 29.34 & 1.96 \\
\hline 2 & 632034 & 215087 & 29.39 & 1.96 \\
\hline 3 & 681584 & 231874 & 29.39 & 1.96 \\
\hline mean \pm SD & & & & $1.964 \pm 0.02 \%$ \\
\hline
\end{tabular}

${ }^{*}$ Concentration deoxyarbutin in the formulation is $2 \%$. Total deoxyarbutin founded in the formulation represented as a mean \pm SD (standard deviation) of 3 observations.

\section{CONCLUSION}

The developed HPLC analytical method meets the validation criteria made by ICH. The optimum condition is performed using column C18, UV detector $225 \mathrm{~nm}$, methanol: water $(60: 40 \mathrm{v} / \mathrm{v})$ as the mobile phase with isocratic elution, the flow rate at $1 \mathrm{ml} / \mathrm{min}$ and running time is 8 min. Total deoxyarbutin was found in anhydrous emulsion preparation is $1.964 \pm 0.02 \%$ with $98 \%$ recovery percentage.

\section{AUTHORS CONTRIBUTIONS}

All the authors have contributed equally.

\section{CONFLICT OF INTERESTS}

Declared none

\section{REFERENCES}

1. Boissy RE, Visscher M, DeLong MA. Deoxy arbutin: a novel reversible tyrosinase inhibitor with effective in vivo skin lightening potency. Exp Dermatol 2005;14:601-8.

2. Lin JY, Fisher DE. Melanocyte biology and skin pigmentation. Nature 2007;445:843-50.

3. Tai SS, Lin CG, Wu MH. Evaluation of depigmenting activity by 8-hydroxydaidzein in mouse B16 melanoma cells and human volunteers. Int J Mol Sci 2009;10:4257-66.

4. Surini S, Mellani T. Formulation and physical evaluation of microemulsion and $\mathrm{W} / \mathrm{O} / \mathrm{W}$ multiple emulsions dosage forms with alpha arbutin, lactic acid, and niacinamide as skinwhitening cosmetics. Int J Appl Pharm 2017;9:67-90.

5. Mukul S, Surabhi K, Atul N. Cosmeceuticals for the skin: an overview. Asian J Pharm Clin Res 2011;4:1-6.

6. Arsiwala S, Tahiliani S, Jerajani H. Evaluation of image blanc complexion lighter and image blanc spot lightener for hyperpigmentation in face and neck. Asian J Pharm Clin Res 2013;6:90-3.

7. Briganti S, Camera E, Picardo M. Chemical and instrumental approaches to treat hyperpigmentation. Pigment Cell Res 2003;16:101-10.

8. Videira IF, Moura DF, Magina S. Mechanisms regulating melanogenesis. An Bras Dermatol 2013;88:76-83.
9. Hu ZM, Zhou Q Lei TC. Effects of hydroquinone and its glucoside derivatives on melanogenesis and antioxidation: biosafety as skin whitening agents. J Dermatol Sci 2009;55:179-84.

10. Petit L, Pierard GE. Skin-lightening products revisited. Int J Cosmet Sci 2003;25:169-81.

11. Kim YJ, Uyama H. Tyrosinase inhibitors from natural and synthetic sources: structure, inhibition mechanism and perspective for the future. Cell Mol Life Sci 2005;62:1707-23.

12. Yang $\mathrm{CH}$, Chang NF, Chen YS. Comparative study on the photostability of arbutin and deoxy arbutin: sensitivity to ultraviolet radiation and enhanced photostability by the watersoluble sunscreen, benzophenone-4. Biosci Biotechnol Biochem 2013;77:1127-30.

13. Suitthimeathegorn O, Jaitely V, Florence AT. Novel anhydrous emulsions: formulation as controlled release vehicles. Int J Pharm 2005;298:367-71.

14. Carvalho VF, de Lemos DP, Vieira CS. Potential of non-aqueous microemulsions to improve the delivery of lipophilic drugs to the skin. AAPS PharmSciTech 2017;18:1739-49.

15. International Conference on Harmonization I. Validation of analytical procedures: Text and Methodology, Q2(R1). Switzerland, Geneva; 1994.

16. Synder LR. Practical HPLC method development Second Edition New York: Jhon Willey and Sons inc; 1997.

17. Karyn MU, Steven $\mathrm{W}$ Hansen, Jennifer $S$ Amoo, Allison $P$ Bernstein, Mary Ellen P McNally. Precision of internal standard and external standard methods in high-performance liquid chromatography. LCGC Magazine. Rio de Janeiro; 2015.

18. Muchtaridi M, Musfiroh I. Off-line SPE-GC/MS analysis of lead compounds aromatherapy in blood plasma of mice of essential oils materials from indonesian aromatic plants. Asian J Chem 2012;24:5124.

19. Kurniati Y, Aryanti AD, Ramdhani D. Design of hydroquinone indicator strip based on polymethylmethacrylate (Pmma) for identification of hydroquinone in whitening cosmetics: a case study in bandung indonesia. Int J Pharm Pharm Sci 2016;8:354-9.

20. Ermer J. Method validation in pharmaceutical analysis. Analytical Validation within the Pharmaceutical Environment. In: Ermer J Miller JHMcB. Weinheim: Wiley-VCH Verlag GmbH and Co. KGaA; 2005. 